\title{
Gastrostomy tube placement increases the risk of ventriculoperitoneal shunt infection: a multiinstitutional study
}

\author{
*Wajd N. Al-Holou, MD, ${ }^{1}$ Thomas J. Wilson, MD, ${ }^{2}$ Zarina S. Ali, MD, ${ }^{3}$ Ryan P. Brennan, MD, ${ }^{4}$ \\ Kelly J. Bridges, MD, ${ }^{5}$ Tannaz Guivatchian, MD, ${ }^{6}$ Ghaith Habboub, MD, ${ }^{4}$ Ajit A. Krishnaney, MD, ${ }^{4}$ \\ Giuseppe Lanzino, MD, ${ }^{7}$ Kendall A. Snyder, MD, Tracy M. Flanders, MD, ${ }^{7}$ Khoi D. Than, MD, ${ }^{5}$ and \\ Aditya S. Pandey, MD8
}

\begin{abstract}
'Department of Neurosurgery, Wayne State University, Detroit, Michigan; 'Department of Neurosurgery, Stanford University, Stanford, California; ${ }^{3}$ Department of Neurosurgery, University of Pennsylvania, Philadelphia, Pennsylvania; ${ }^{4}$ Department of Neurosurgery, Cleveland Clinic, Cleveland, Ohio; ${ }^{5}$ Department of Neurosurgery, Oregon Health \& Science University, Portland, Oregon; ${ }^{6}$ Department of Internal Medicine, Division of Gastroenterology and Hepatology, and ${ }^{8}$ Department of Neurosurgery, University of Michigan, Ann Arbor, Michigan; and 'Department of Neurosurgery, Mayo Clinic, Rochester, Minnesota
\end{abstract}

\begin{abstract}
OBJECTIVE Gastrostomy tube placement can temporarily seed the peritoneal cavity with bacteria and thus theoretically increases the risk of shunt infection when the two procedures are performed contemporaneously. The authors hypothesized that gastrostomy tube placement would not increase the risk of ventriculoperitoneal shunt infection. The object of this study was to test this hypothesis by utilizing a large patient cohort combined from multiple institutions.

METHODS A retrospective study of all adult patients admitted to five institutions with a diagnosis of aneurysmal subarachnoid hemorrhage between January 2005 and January 2015 was performed. The primary outcome of interest was ventriculoperitoneal shunt infection. Variables, including gastrostomy tube placement, were tested for their association with this outcome. Standard statistical methods were utilized.
\end{abstract}

RESULTS The overall cohort consisted of 432 patients, $47 \%$ of whom had undergone placement of a gastrostomy tube. The overall shunt infection rate was $9 \%$. The only variable that predicted shunt infection was gastrostomy tube placement $(p=0.03, O R 2.09,95 \% \mathrm{Cl} 1.07-4.08)$, which remained significant in the multivariate analysis $(p=0.04,0 R 2.03$, $95 \% \mathrm{Cl} 1.04-3.97)$. The greatest proportion of shunts that became infected had been placed more than 2 weeks (25\%) and $1-2$ weeks (18\%) prior to gastrostomy tube placement, but the temporal relationship between shunt and gastrostomy was not a significant predictor of shunt infection.

CONCLUSIONS Gastrostomy tube placement significantly increases the risk of ventriculoperitoneal shunt infection. https://thejns.org/doi/abs/10.3171/2018.5.JNS18506

KEYWORDS ventriculoperitoneal shunt; gastrostomy tube; cerebrospinal fluid; shunt infection; hydrocephalus

A VARIETY of pathologies result in hydrocephalus necessitating cerebrospinal fluid (CSF) diversion, most commonly achieved through ventriculoperitoneal (VP) shunting. Among patients with aneurysmal subarachnoid hemorrhage (SAH), most studies report that $15 \%-20 \%$ of patients develop shunt-dependent hydrocephalus. ${ }^{20}$ Unfortunately, shunt infections are not uncommon and pose significant morbidity to patients. Potential risk factors for shunt-related infections include a longer duration of surgery, increased number of people in the operating room, previous shunt infection, history of brain infection, immune deficiency, younger age, shunt revision, and poor clinical condition of the patient. ${ }^{1,5,6,9,10,13,17}$ An evaluation of patients with SAH-associated hydrocephalus revealed that patients with higher presentation Hunt and Hess scores and those who underwent clip ligation 
had higher rates of shunt infection. ${ }^{4}$ Protocols designed to minimize these risk factors are in place at many institutions in order to decrease shunt infections.

Patients who require VP shunting frequently require concomitant tracheostomy for airway protection and to facilitate weaning of mechanical ventilation as well as gastrostomy tube placement for the administration of enteral nutrition. Gastrostomy tube placement can temporarily seed the peritoneal cavity with bacteria and thus theoretically increases the risk of shunt infection when the two procedures are performed contemporaneously. Data from

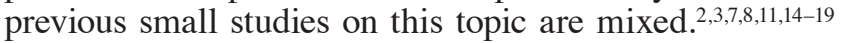
Recently, authors of a systematic review concluded that the combination is safe, without an increased risk of infection. ${ }^{12}$ However, these authors admitted that the reviewed studies were poor quality; therefore, drawing conclusions from this systematic review is problematic. We hypothesized that gastrostomy tube placement would not increase the risk of VP shunt infection. We set out to test this hypothesis by utilizing a large patient cohort combined from multiple institutions to determine the safety of VP shunting and gastrostomy tube placement in adults.

\section{Methods \\ Study Design}

This cohort study was conducted at five institutions: University of Michigan, Cleveland Clinic, Mayo Clinic, University of Pennsylvania, and Oregon Health \& Science University. The institutional review boards at all five contributing institutions approved this study, and data were obtained by retrospective review of medical records including radiographic images. Each institution queried the institutional electronic medical records to identify all adult patients (18 years of age and older) who had been admitted with a diagnosis of aneurysmal SAH between January 2005 and January 2015. Medical records from the identified cohort were reviewed to identify the subset of patients who had developed hydrocephalus requiring placement of a VP shunt.

For this cohort, a detailed chart review was performed and the following data were abstracted: sex, age at SAH admission, aneurysm treatment modality (endovascular coiling vs microsurgical clipping), gastrostomy tube placement, date of gastrostomy tube placement, date of VP shunt placement, ventriculostomy, ventriculostomy duration, ventriculostomy infection, shunt revision, date of shunt revision, shunt infection, date of shunt infection diagnosis, use of postoperative shunt antibiotic prophylaxis, use of an antibiotic-impregnated shunt catheter, gastrostomy tube site infection, Hunt and Hess grade, and modified Fisher grade. We defined shunt infection as the presence of a positive CSF culture or as CSF studies and clinical presentation strongly suggesting infection, such as an elevated CSF white blood cell count, presence of bacteria on CSF Gram stain, and/or low glucose levels combined with clinical signs of meningitis or shunt failure that ultimately led to externalization of the shunt or revision or replacement of the shunt.

Each institution collected data independently and then sent anonymized data to the University of Michigan for compilation and initial analysis. All involved institutions participated in the final analyses.

\section{Primary Outcome of Interest}

The primary outcome of interest was VP shunt infection. Variables were tested for their association with this outcome.

\section{Statistical Analysis}

Statistical analysis was performed using commercially available software (SPSS version 24, IBM Corp.). All categorical data were assessed using the chi-square test or Fisher's exact test, as appropriate. All continuous data were compared using the Student t-test. For purposes of multivariate logistic regression, we planned a priori to include into the subsequent multivariate analysis all variables with $\mathrm{p}<0.20$ in the univariate analysis. Statistical significance was considered to be $\mathrm{p}<0.05$.

\section{Results \\ Cohort Summary}

The overall cohort (Table 1) consisted of 432 patients who had presented with aneurysmal SAH and subsequently had CSF diversion with a VP shunt. The majority of patients were female (67\%). Average age was 58 years. Shunt infections occurred in 40 patients (9\%). A total of 201 patients $(47 \%)$ also underwent placement of a gastrostomy tube. The cohort was nearly evenly split between microsurgical clip ligation (49\%) and coil embolization (51\%) as the method of treatment. The overwhelming majority of the cohort (98\%) received postoperative antibiotic prophylaxis following VP shunting. Antibiotic-impregnated catheters were used in most cases (68\%). The mean and median follow-up were 592 and 233 days, respectively, with $55 \%$ of patients having at least 6 months of documented follow-up and $40 \%$ having at least 1 year of follow-up.

\section{Comparison of Patients With and Without Shunt Infection}

The group that developed a VP shunt infection and the group that remained infection free were similar in terms of sex, age, radiological and clinical SAH severity, treatment modality, ventriculostomy utilization, postoperative antibiotic use, and utilization of antibiotic-impregnated shunt catheters (Table 1). The group with an infection had a significantly higher proportion of patients who underwent gastrostomy tube placement $(63 \%)$ than the group without infection $(45 \% ; \mathrm{p}=0.03)$. The relative risk for shunt infection with a gastrostomy tube was 1.4.

\section{Predictors of Shunt Infection}

Univariate logistic regression was used to test variables on their ability to predict the occurrence of a VP shunt infection (Table 2). The only variable that predicted shunt infection was gastrostomy tube placement $(\mathrm{p}=0.03$, OR $2.09,95 \%$ CI $1.07-4.08$ ). We planned a priori to include any variables with $\mathrm{p}<0.20$ in the univariate analysis into the subsequent multivariate analysis, so we included both gastrostomy tube placement and sex. In the multivariate analysis, gastrostomy tube placement remained a signifi- 
TABLE 1. Summary of data for the entire cohort, the cohort with shunt infection, and the cohort without shunt infection

\begin{tabular}{|c|c|c|c|c|}
\hline Parameter & Total & Shunt Infection & No Shunt Infection & $\mathrm{p}$ Value \\
\hline No. of patients & 432 & 40 & 392 & \\
\hline Sex & & & & 0.17 \\
\hline Male & $142(33 \%)$ & $17(43 \%)$ & $125(32 \%)$ & \\
\hline Female & $290(67 \%)$ & $23(57 \%)$ & $267(68 \%)$ & \\
\hline Age at SAH admission in yrs (SD) & $58(12)$ & $56(11)$ & $58(12)$ & 0.42 \\
\hline $\mathrm{HH}$ grade $^{*}$ & & & & 0.80 \\
\hline I & $5(2 \%)$ & $1(3 \%)$ & $4(1 \%)$ & \\
\hline$\|$ & $84(26 \%)$ & $6(21 \%)$ & $78(27 \%)$ & \\
\hline III & $78(25 \%)$ & $7(24 \%)$ & $71(25 \%)$ & \\
\hline IV & $81(26 \%)$ & $7(24 \%)$ & $74(26 \%)$ & \\
\hline V & $69(22 \%)$ & $8(28 \%)$ & $61(21 \%)$ & \\
\hline Modified Fisher grade* & & & & 0.27 \\
\hline 0 & $0(0 \%)$ & $0(0 \%)$ & $0(0 \%)$ & \\
\hline 1 & $3(1 \%)$ & $0(0 \%)$ & $3(1 \%)$ & \\
\hline 2 & $16(5 \%)$ & $0(0 \%)$ & $16(6 \%)$ & \\
\hline 3 & $77(24 \%)$ & $8(29 \%)$ & $69(24 \%)$ & \\
\hline 4 & $220(70 \%)$ & $20(71 \%)$ & $200(69 \%)$ & \\
\hline Aneurysm treatment ${ }^{*}$ & & & & 0.56 \\
\hline Microsurgical clip & $206(49 \%)$ & $17(45 \%)$ & $189(50 \%)$ & \\
\hline Endovascular coil & $212(51 \%)$ & $21(55 \%)$ & $191(50 \%)$ & \\
\hline Ventriculostomy ${ }^{*}$ & $389 / 420(93 \%)$ & $36 / 37(97 \%)$ & $353 / 383(92 \%)$ & 0.22 \\
\hline Ventriculostomy infection* & $18 / 422(4 \%)$ & $3 / 37(8 \%)$ & $15 / 385(4 \%)$ & 0.23 \\
\hline Gastrostomy tube & $201(47 \%)$ & $25(63 \%)$ & $176(45 \%)$ & 0.03 \\
\hline Gastrostomy site infection & $6(1 \%)$ & $1(3 \%)$ & $5(1 \%)$ & 0.44 \\
\hline Postop antibiotic prophylaxis & $422(98 \%)$ & $39(98 \%)$ & $383(98 \%)$ & 0.99 \\
\hline Antibiotic-impregnated shunt catheter* & $178 / 261(68 \%)$ & $13 / 20(65 \%)$ & $165 / 241(68 \%)$ & 0.75 \\
\hline
\end{tabular}

$\mathrm{HH}=$ Hunt and Hess; $\mathrm{SD}=$ standard deviation.

Boldface type indicates statistical significance.

* Percentages are based on the total number of cases for which data were available.

cant predictor ( $\mathrm{p}=0.04$, OR $2.03,95 \%$ CI $1.04-3.97)$, whereas sex was not significant.

\section{Gastrostomy Tube Subgroup Analysis for Predictors of Shunt Infection}

We performed logistic regression analysis to examine for predictors of shunt infection among the subgroup of patients who underwent placement of a gastrostomy tube (Table 3). None of the variables analyzed were significant predictors of shunt infection.

Table 4 shows the temporal relationship between gastrostomy tube and VP shunt placement and the number of shunts that developed an infection in each time period. The majority of shunts were placed after gastrostomy tube placement (74\%). The highest proportion of shunts that became infected were placed more than 2 weeks $(25 \%)$ and 1-2 weeks (18\%) prior to gastrostomy tube placement. Of note, the number of shunts placed in this same period was low. Only 8 shunts $(4 \%)$ were placed more than 2 weeks before gastrostomy tube placement, and 2 (25\%) of these became infected.

\section{Comparison of Contributing Institutions}

Five institutions contributed patients to the overall cohort. At four of the five contributing institutions, the shunt infection rate was higher in the patients who had a gastrostomy tube (Table 5); this difference was statistically significant at the Mayo Clinic and Oregon Health \& Science University. The exception was the University of Michigan, where the shunt infection rate was higher in the patients without gastrostomy tubes, though not statistically different.

\section{Comparison of Time to Shunt Infection}

Median time from shunt implantation to shunt infection among the group that had a gastrostomy tube and developed a shunt infection was 34 days (IQR 19-74 days; Fig. 1). Median time to infection among the group who did not have a gastrostomy tube and developed a shunt infection was 99 days (IQR 23-392 days). There was no significant difference in the time to infection for these two groups $(p=0.17)$.

\section{Discussion}

Neurosurgical patients requiring placement of a VP shunt frequently have a contemporaneous need for placement of a gastrostomy tube. Most institutions report a shunt infection rate of approximately $10 \%$, which is simi- 
TABLE 2. Univariate and multivariate logistic regression analyses of variables on their ability to predict shunt infection

\begin{tabular}{|c|c|c|c|c|}
\hline \multirow[b]{2}{*}{ Variable } & \multicolumn{2}{|c|}{ Univariate Analysis } & \multicolumn{2}{|c|}{ Multivariate Analysis } \\
\hline & p Value & OR $(95 \% \mathrm{Cl})$ & p Value & OR $(95 \% \mathrm{Cl})$ \\
\hline Female sex & 0.17 & $0.63(0.32-1.22)$ & 0.22 & $0.66(0.34-1.29)$ \\
\hline Age & 0.42 & $0.99(0.96-1.02)$ & & \\
\hline Coil embolization & 0.56 & $1.22(0.63-2.39)$ & & \\
\hline Ventriculostomy & 0.23 & $3.41(0.45-25.64)$ & & \\
\hline Ventriculostomy infection & 0.62 & $1.46(0.32-6.71)$ & & \\
\hline Gastrostomy & 0.03 & $2.09(1.07-4.08)$ & 0.04 & $2.03(1.04-3.97)$ \\
\hline Gastrostomy infection & 0.31 & $6.76(0.66-69.06)$ & & \\
\hline $\mathrm{HH}$ grade IV-V & 0.62 & $1.21(0.56-2.60)$ & & \\
\hline Modified Fisher grade 3-4 & 0.54 & $1.91(0.25-14.71)$ & & \\
\hline Postop antibiotics & 0.99 & $1.00(0.99-1.01)$ & & \\
\hline Antibiotic-impregnated catheter & 0.45 & $0.70(0.29-1.74)$ & & \\
\hline
\end{tabular}

For dichotomous variables, the listed value is the non-reference value. Boldface type indicates statistical significance.

lar to the rate in this study. Placement of a gastrostomy tube can theoretically seed the peritoneal cavity with bacteria from the gastrointestinal tract, thereby potentially increasing the risk of shunt infection. Previous studies have conflicting conclusions regarding the risk posed by gastrostomy tube and VP shunt placement. ${ }^{2,3,7,8,11,14-19}$ Given the frequent need for both of these procedures in the same patient, we believed it was important to understand the associated risk. We hypothesized that gastrostomy tube placement would not be a risk factor for VP shunt infection. We set out to perform a multiinstitutional study in order to compile a large data set to test this hypothesis. However, the data led us to reject this hypothesis and conclude that gastrostomy tube placement is a significant risk factor for VP shunt infection.

Five institutions contributed to the current study. The overall shunt infection rate was $9 \%$, which is in line with rates in other recent studies on the topic. ${ }^{5,12,17}$ Shunt infection rates were similar across the contributing institutions, ranging from $4 \%$ to $13 \%$. Each institution made a relatively equal contribution to the overall data set. The proportion of patients who underwent gastrostomy tube placement ranged from $28 \%$ to $71 \%$, suggesting variability across institutions in the management of patients with $\mathrm{SAH}$ and the need for gastrostomy tube placement.

TABLE 3. Univariate logistic regression analysis of variables to predict shunt infection among the subgroup that had contemporaneous gastrostomy tube placement

\begin{tabular}{lcc}
\hline \multicolumn{1}{c}{ Variable } & p Value & OR $(95 \% \mathrm{CI})$ \\
\hline Female sex & 0.41 & $0.70(0.30-1.63)$ \\
\hline Age & 0.30 & $0.98(0.95-1.02)$ \\
\hline Coil embolization & 0.97 & $0.98(0.41-2.34)$ \\
\hline Time from shunt to gastrostomy & 0.49 & $0.99(0.99-1.00)$ \\
\hline Gastrostomy prior to shunt & 0.47 & $0.71(0.29-1.77)$ \\
\hline
\end{tabular}

For dichotomous variables, the listed value is the non-reference value. No multivariate analysis was performed since none of the variables met the a priori criteria for inclusion.
The group of patients that developed a shunt infection and the group that did not were similar in terms of age, sex, disease severity (i.e., Hunt and Hess grade and modified Fisher grade), use of postoperative antibiotic prophylaxis, and use of antibiotic-impregnated shunt catheters. The groups differed only in the relative proportions of patients who underwent placement of a gastrostomy tube: $63 \%$ and $45 \%$ for the groups with and without infection, respectively. Testing the variables for their ability to predict a shunt infection revealed that only placement of a gastrostomy tube was a significant predictor of shunt infection on both univariate and multivariate analyses. Placement of a gastrostomy tube more than doubled the odds (95\% CI 1.04-3.97) of developing a shunt infection.

The authors of a recent systematic review found a $12.5 \%$ infection rate in patients undergoing contemporaneous VP shunt and gastrostomy tube placement. ${ }^{12}$ They concluded that while this rate was high, it was acceptable and that a VP shunt should not be considered a contraindication to gastrostomy tube placement. However, several problems exist regarding this conclusion. First, by the authors' own admission, the included studies were poor quality. With poor input data, the output cannot be considered reliable. We found a similar rate of shunt infection, $12.9 \%$, in the

TABLE 4. Comparison of shunt infection rates across time periods for the relationship between VP shunt placement and gastrostomy tube placement

\begin{tabular}{lcc}
\hline \multicolumn{1}{c}{ Variable } & $\begin{array}{c}\text { No. of } \\
\text { Shunts (\%) }\end{array}$ & $\begin{array}{c}\text { No. of Infected } \\
\text { Shunts (\%) }\end{array}$ \\
\hline Gastrostomy >2 wks before shunt & $59(30)$ & $5(8)$ \\
\hline Gastrostomy 1-2 wks before shunt & $43(22)$ & $4(9)$ \\
\hline Gastrostomy 0-1 wk before shunt & $46(23)$ & $8(17)$ \\
\hline Shunt 0-1 wk before gastrostomy & $26(13)$ & $3(12)$ \\
\hline Shunt 1-2 wks before gastrostomy & $17(9)$ & $3(18)$ \\
\hline Shunt >2 wks before gastrostomy & $8(4)$ & $2(25)$ \\
\hline
\end{tabular}

Percentages are based on 199 gastrostomy tubes, for which the time of placement was known. 
TABLE 5. Shunt infection rates across contributing institutions and among patients with and without a contemporaneous gastrostomy tube

\begin{tabular}{lccrc}
\hline \multicolumn{1}{c}{ Institution } & $\begin{array}{c}\text { Shunt Infection } \\
\text { Rate }\end{array}$ & $\begin{array}{c}\text { Shunt Infection in Patients } \\
\text { w/ Gastrostomy Tube }\end{array}$ & $\begin{array}{c}\text { Shunt Infection Rate in Patients } \\
\text { w/o Gastrostomy Tube }\end{array}$ & $\begin{array}{c}\mathrm{p} \\
\text { Value }\end{array}$ \\
\hline University of Michigan & $11 \%(10 / 89)$ & $7 \%(3 / 45)$ & $16 \%(7 / 44)$ & 0.20 \\
\hline Cleveland Clinic & $12 \%(10 / 84)$ & $15 \%(9 / 60)$ & $4 \%(1 / 24)$ & 0.27 \\
\hline Mayo Clinic & $8 \%(7 / 83)$ & $22 \%(5 / 23)$ & $3 \%(2 / 60)$ & 0.02 \\
\hline University of Pennsylvania & $13 \%(8 / 60)$ & $14 \%(5 / 36)$ & $13 \%(3 / 24)$ & 0.99 \\
\hline Oregon Health \& Science University & $4 \%(5 / 116)$ & $11 \%(4 / 38)$ & $1 \%(1 / 78)$ & $\mathbf{0 . 0 4}$ \\
\hline
\end{tabular}

Boldface type indicates statistical significance.

group with gastrostomy tube placement. However, the important missing piece of data from their systematic review is the rate of infection in a similar group that did not undergo concurrent gastrostomy tube placement. In that group, our observed rate of shunt infections was 6.1\%less than half the rate. While a $12 \%$ infection rate may be acceptable, particularly given that neither placement of a VP shunt nor placement of a gastrostomy tube is an optional or truly elective procedure, our data suggest that we cannot ignore gastrostomy tube placement as a risk factor for infection. A recent study in children corroborates our finding in adults and suggested a hazard ratio of 2.0 for gastrostomy tube placement. ${ }^{17}$

If we accept gastrostomy tube placement as a risk factor for shunt infection, a logical follow-up question is, "How do we minimize the risk?" We in no way suggest that a shunt or gastrostomy tube should not be placed. Our hope was to identify variables correlated with increased infection in order to guide efforts to minimize such infections. Our subgroup analysis of the patients who underwent contemporaneous gastrostomy tube placement revealed no factors predictive of shunt infection. Specifically, neither the order of VP shunt and gastrostomy tube placement nor the time interval between VP shunt and gastrostomy placement was a significant predictor of shunt infection. Table 4 ,

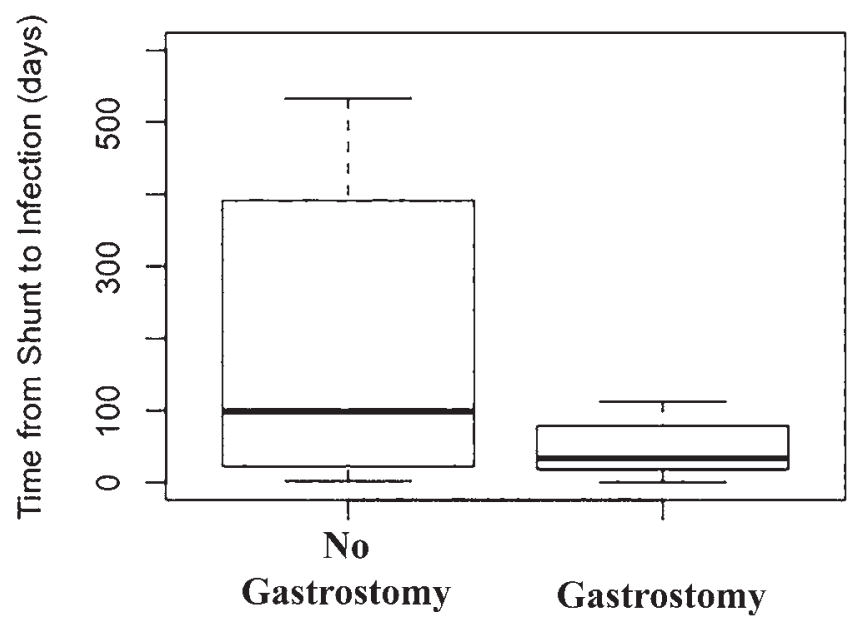

FIG. 1. Box plot showing the time to infection following VP shunt insertion, comparing the group of patients who had a gastrostomy tube and the group that did not. Time 0 was considered the day of VP shunt creation. however, does seem to show a trend toward a lower risk of shunt infection when the gastrostomy tube is placed before the shunt. For shunts placed at least 1 week after gastrostomy tube placement, the infection rate was $9 \%$. In comparison, when the shunt was placed less than 1 week after gastrostomy or prior to gastrostomy, the infection rate was $17 \%$. While this is only a trend, it is a strong enough trend to warrant consideration. A prospective study is needed to clarify this issue. On the basis of our data, however, we recommend, when reasonable, placing the gastrostomy tube first and the VP shunt at least 1 week after the gastrostomy tube. Importantly, this contradicts the recommendation of Oterdoom and colleagues in their recent systematic review. ${ }^{12}$ In the rare situation in which gastrostomy tube placement is deemed unnecessary, consideration could be given to other alternatives. A prospective study may be helpful in identifying additional risk-mitigation strategies such as prolonged prophylactic antibiotics administered prior to the gastrostomy, after the gastrostomy, or both.

There are several limitations to the current study. First, it is a retrospective study with all of the inherent problems and biases of such a study. With the multiple institutions contributing, we have the advantage of incorporating a variety of standards and practice algorithms, but this is also a weakness. We may not have accounted for biases at different institutions that led to things such as the observed difference in the infection rate between the group without gastrostomy tubes at the University of Michigan (16\%) and the group without gastrostomy tubes at Oregon Health \& Science University (1\%). Part of this may be accounted for by differences in record keeping and documentation. Additionally, although five different high-volume institutions participated in this study, the total number of infections was still low, which may limit our analyses. The study is also limited in that all shunt infections may not be accounted for. Specifically, any shunt infection recognized and treated outside of the institution to which the patient originally presented would not be accounted for. Despite these limitations, the strengths of the study, including its multiinstitutional nature, large cohort, and background homogeneity of the cohort given that it is made up of SAH patients, lead us to believe that it is the most definitive study on the topic to date.

\section{Conclusions}

Gastrostomy tube placement significantly increases the risk of VP shunt infection. On the basis of our data, 
we recommend, when reasonable, placing the gastrostomy tube first and the VP shunt at least 1 week after the gastrostomy. No additional risk-mitigation strategies were identified. While this study should be considered when determining optimal practices, we believe that the study highlights the need for a prospective study designed to identify risk-reduction strategies.

\section{References}

1. Albanese A, De Bonis P, Sabatino G, Capone G, Marchese E, Vignati A, et al: Antibiotic-impregnated ventriculo-peritoneal shunts in patients at high risk of infection. Acta Neurochir (Wien) 151:1259-1263, 2009

2. Baird R, Salasidis R: Percutaneous gastrostomy in patients with a ventriculoperitoneal shunt: case series and review. Gastrointest Endosc 59:570-574, 2004

3. Cairns A, Geraghty J, Al-Rifai A, Babbs C: Percutaneous endoscopic gastrostomy and ventriculoperitoneal shunts: a dangerous combination? Dig Endosc 21:228-231, 2009

4. Chalouhi N, Whiting A, Anderson EC, Witte S, Zanaty M, Tjoumakaris S, et al: Comparison of techniques for ventriculoperitoneal shunting in 523 patients with subarachnoid hemorrhage. J Neurosurg 121:904-907, 2014

5. Choux M, Genitori L, Lang D, Lena G: Shunt implantation: reducing the incidence of shunt infection. $\mathbf{J}$ Neurosurg 77:875-880, 1992

6. Giannetti AV, Pimenta FG, Clemente WT: Does the simultaneous use of a neuroendoscope influence the incidence of ventriculoperitoneal shunt infection? World Neurosurg 98:171-175, 2017

7. Graham SM, Flowers JL, Scott TR, Lin F, Rigamonti D: Safety of percutaneous endoscopic gastrostomy in patients with a ventriculoperitoneal shunt. Neurosurgery 32:932934, 1993

8. Kim JS, Park YW, Kim HK, Cho YS, Kim SS, Youn NR, et al: Is percutaneous endoscopic gastrostomy tube placement safe in patients with ventriculoperitoneal shunts? World J Gastroenterol 15:3148-3152, 2009

9. Li G, Pu K, Cao Y, Wang J, Sun Z, Li Q: The role of antibiotic prophylaxis in shunt surgery. World Neurosurg 108:548-554, 2017

10. Merkler AE, Ch'ang J, Parker WE, Murthy SB, Kamel H: The rate of complications after ventriculoperitoneal shunt surgery. World Neurosurg 98:654-658, 2017

11. Nabika S, Oki S, Sumida M, Isobe N, Kanou Y, Watanabe Y: Analysis of risk factors for infection in coplacement of percutaneous endoscopic gastrostomy and ventriculoperitoneal shunt. Neurol Med Chir (Tokyo) 46:226-230, 2006

12. Oterdoom LH, Marinus Oterdoom DL, Ket JCF, van Dijk JMC, Scholten P: Systematic review of ventricular peritoneal shunt and percutaneous endoscopic gastrostomy: a safe combination. J Neurosurg 127:899-904, 2017

13. Rammos S, Klopfenstein J, Augspurger L, Wang H, Wagenbach A, Poston J, et al: Conversion of external ventricular drains to ventriculoperitoneal shunts after aneurysmal subarachnoid hemorrhage: effects of site and protein/red blood cell counts on shunt infection and malfunction. J Neurosurg 109:1001-1004, 2008 (Erratum in J Neurosurg 110:196, 2009)

14. Roeder BE, Said A, Reichelderfer M, Gopal DV: Placement of gastrostomy tubes in patients with ventriculoperitoneal shunts does not result in increased incidence of shunt infection or decreased survival. Dig Dis Sci 52:518-522, 2007

15. Sane SS, Towbin A, Bergey EA, Kaye RD, Fitz CR, Albright $\mathrm{L}$, et al: Percutaneous gastrostomy tube placement in patients with ventriculoperitoneal shunts. Pediatr Radiol 28:521523, 1998

16. Schulman AS, Sawyer RG: The safety of percutaneous endoscopic gastrostomy tube placement in patients with existing ventriculoperitoneal shunts. JPEN J Parenter Enteral Nutr 29:442-444, 2005

17. Simon TD, Butler J, Whitlock KB, Browd SR, Holubkov R, Kestle JR, et al: Risk factors for first cerebrospinal fluid shunt infection: findings from a multi-center prospective cohort study. J Pediatr 164:1462-1468.e2, 2014

18. Taylor AL, Carroll TA, Jakubowski J, O'Reilly G: Percutaneous endoscopic gastrostomy in patients with ventriculoperitoneal shunts. Br J Surg 88:724-727, 2001

19. Vui HC, Lim WC, Law HL, Norwani B, Charles VU: Percutaneous endoscopic gastrostomy in patients with ventriculoperitoneal shunt. Med J Malaysia 68:389-392, 2013

20. Xie Z, Hu X, Zan X, Lin S, Li H, You C: Predictors of shuntdependent hydrocephalus after aneurysmal subarachnoid hemorrhage? A systematic review and meta-analysis. World Neurosurg 106:844-860, 2017

\section{Disclosures}

Dr. Than has been a consultant for Bioventus.

\section{Author Contributions}

Conception and design: Al-Holou, Wilson, Guivatchian, Pandey. Acquisition of data: Al-Holou, Wilson, Ali, Brennan, Bridges, Habboub, Krishnaney, Lanzino, Snyder, Flanders, Than, Pandey. Analysis and interpretation of data: Al-Holou, Wilson. Drafting the article: Al-Holou, Wilson, Guivatchian. Critically revising the article: all authors. Reviewed submitted version of manuscript: all authors. Approved the final version of the manuscript on behalf of all authors: Al-Holou, Wilson. Statistical analysis: Al-Holou, Wilson. Administrative/technical/material support: Al-Holou, Wilson, Ali, Brennan, Bridges, Habboub, Krishnaney, Lanzino, Snyder, Flanders, Than, Pandey. Study supervision: Al-Holou, Wilson, Pandey.

\section{Correspondence}

Wajd N. Al-Holou: Wayne State University, Detroit, MI. walholou@med.wayne.edu. 